\title{
Signatures of 3-6 day planetary waves in the equatorial mesosphere and ionosphere
}

\author{
H. Takahashi ${ }^{1}$, C. M. Wrasse ${ }^{1}$, D. Pancheva ${ }^{2}$, M. A. Abdu ${ }^{1}$, I. S. Batista ${ }^{1}$, L. M. Lima ${ }^{3}$, P. P. Batista ${ }^{1}$, B. R. Clemesha ${ }^{1}$, \\ and K. Shiokawa ${ }^{4}$ \\ ${ }^{1}$ Instituto Nacional de Pesquisas Espaciais, INPE, CP-515, 12245-970 São José dos Campos, SP, Brazil \\ ${ }^{2}$ Department of Electronic \& Electrical Engineering, University of Bath, Bath, BA2 7AY, UK \\ ${ }^{3}$ Dept. Física, Universidade Estadual de Paraíba, Campina Grande, PB, Brazil \\ ${ }^{4}$ Solar Terrestrial Environmental Laboratory, STEL, Nagoya University, Toyokawa, Aichi 442-8507, Japan
}

Received: 22 August 2006 - Revised: 16 November 2006 - Accepted: 27 November 2006 - Published: 21 December 2006

\begin{abstract}
Common periodic oscillations have been observed in meteor radar measurements of the MLT winds at Cariri $\left(7.4^{\circ} \mathrm{S}, 36.5^{\circ} \mathrm{W}\right)$ and Ascension Island $\left(7.9^{\circ} \mathrm{S}, 14.4^{\circ} \mathrm{W}\right)$ and in the minimum ionospheric virtual height, $h^{\prime} F$, measured at Fortaleza $\left(3.9^{\circ} \mathrm{S}, 38.4^{\circ} \mathrm{W}\right)$ in 2004 , all located in the near equatorial region. Wavelet analysis of these time series reveals that there are 3-4-day, 6-8-day and 12-16-day oscillations in the zonal winds and $h^{\prime} F$. The 3-4 day oscillation appeared as a form of a wave packet from 7-17 August 2004. From the wave characteristics analyzed this might be a 3.5-day Ultra Fast Kelvin wave. The 6-day oscillation in the mesosphere was prominent during the period of August to November. In the ionosphere, however, it was apparent only in November. Spectral analysis suggests that this might be a 6.5-day wave previously identified. The 3.5-day and 6.5day waves in the ionosphere could have important roles in the initiation of equatorial spread $F$ (plasma bubble). These waves might modulate the post-sunset $\boldsymbol{E} \times \boldsymbol{B}$ uplifting of the base of the F-layer via the induced lower thermosphere zonal wind and/or the E-region conductivity.
\end{abstract}

Keywords. Meteorology and atmospheric dynamics (Waves and tides) - Ionosphere (Equatorial ionosphere; Ionosphereatmosphere interactions)

\section{Introduction}

Vertical coupling of the Earth's atmosphere from the troposphere to the middle atmosphere-ionosphere-thermosphere through dynamical processes (tides, gravity waves and planetary waves) is important to the understanding of atmospheric momentum and energy flow. Gravity waves generated in the troposphere by meteorological activities propagate upwards into the mesosphere to lower thermosphere (MLT) re-

Correspondence to: $\mathrm{H}$. Takahashi

(hisaotak@laser.inpe.br) gion. Tidal winds in the MLT region play crucial roles in the ionospheric E- and F-region wind dynamo field. An influence of planetary waves on the ionosphere was suggested by Brown and Williams (1971) who showed a correlation between stratospheric pressure variations and E-region electron density. Pancheva and Lysenko (1988) reported the existence of quasi-two-day oscillations of the F-region maximum electron concentration and related these to the analogous oscillation of the meteor winds. Chen (1992) observed 2-day oscillations in the amplitude of the equatorial ionization anomaly and suggested the presence of planetary waves in the equatorial region. Forbes et al. (1997) also reported quasi-twoday oscillations in $f o \mathrm{~F} 2$, which could be connected with the quasi-two-day oscillation in the MLT winds. Pancheva et al. (2002) studied the variation of the peak height of the ionospheric F2-layer, $h m \mathrm{~F} 2$, with 27-day, 16-day and quasi-twoday periods. They reported that the 16-day period must be related to a 16-day modulation of the semidiurnal tide in the MLT region. Concerning the planetary wave oscillation of $f o \mathrm{~F} 2$ and mesospheric wind tidal oscillation Lastovicka and Sauli (1999) has reported similar 5- and 11-day oscillations in the two parameters from the middle to high latitudes. Recent research works revealed that sporadic E-layers are affected indirectly by planetary waves through their nonlinear interaction and modulation of the atmospheric tides at lower altitudes (Haldoupis et al., 2004). However, the complete scheme of the coupling process is not well known.

Planetary scale waves in the equatorial region, Kelvin waves and Rossby-gravity waves are those trapped in the equatorial and low-latitude regions. It is believed that these waves are excited by oscillation of large-scale tropical convections (Holton, 1979). Rossby-gravity waves have 1- to 5day oscillation periods, depending on their horizontal wave number, and they propagate westward. On the other hand, Kelvin waves propagate eastward. According to the oscillation period, these waves are divided into three categories, slow (16-day) (Wallace and Kousky, 1968), fast (6-day)

Published by Copernicus GmbH on behalf of the European Geosciences Union. 
Table 1. Characteristics of Equatorial Kelvin waves from literature.

\begin{tabular}{llllll}
\hline Type & $\begin{array}{l}\text { Period } \\
\text { (day) }\end{array}$ & $\begin{array}{l}\text { Wave number } \\
\text { (dominant) }\end{array}$ & $\begin{array}{l}\text { Phase velocity } \\
(\mathrm{m} / \mathrm{s})(* *)\end{array}$ & $\begin{array}{l}\text { Vertical } \\
\text { wavelength }(\mathrm{km})\end{array}$ & Reference \\
\hline Slow Kelvin & $15(10-20)^{*}$ & 1 & $+15(20-40)$ & $\sim 10$ & Wallace and Kousky (1968) \\
Fast Kelvin & $6(6-10)$ & 1 and 2 & $+70(60-80)$ & $\sim 20$ & Hirota (1979) \\
Ultra Fast Kelvin & $3.5(3-4)$ & 1 and 2 & $+150(120-150)$ & $\sim 60$ & Forbes $(2000)$ \\
\hline
\end{tabular}

$(*)$ : the number in parenthesis indicates the observed period which includes the Doppler shift effect due to background wind flow. (**): Positive (negative) sign means eastward (westward) phase velocity.

(Hirota, 1979) and ultra fast (3.5-day) (Salby et al., 1984). In Table 1 characteristics of the equatorial Kelvin waves are summarized for reference. Kelvin waves at mesospheric heights were first reported by Vincent (1993) and later by Liebermann and Riggin (1997). Takahashi et al. (2002) presented a 3.5-day oscillation of the mesospheric airglow and temperature from a ground-based airglow observation. Most recently, Pancheva et al. (2004) presented MLT wind data analysis from Ascension Island and reported evidence of 2day waves in the meridional wind and 3.5-day waves in the zonal winds.

Evidence concerning equatorial Kelvin waves in the ionosphere has not been well investigated yet. Forbes and Leveroni (1992) reported 16-day oscillations in the equatorial E- and F-layers and suggested their influence on the inospheric wind dynamo. Parish et al. (1994) presented 2- to 16-day period oscillations in the equatorial electrojet. These few observational results, however, are not enough to identify the Kelvin waves in the equatorial ionosphere. With respect to the ultra fast Kelvin waves Forbes (2000) called special attention to their important role in the ionosphere. Because of their long vertical wavelength ( $>50 \mathrm{~km})$, they could penetrate into the MLT and thermosphere regions (100-150 km) transporting energy and momentum from the troposphere. In this connection, Takahashi et al. (2005) presented 2- and 3-4 day oscillations in the F-layer virtual height $\left(h^{\prime} F\right)$ day-to-day variability. Abdu et al. (2006a) also observed planetary wave oscillations (6.5-day and 14-day) in simultaneous measurements of mesospheric winds and equatorial electrojet intensity.

There is an important aspect of the possible influence of Kelvin waves in the equatorial ionosphere. During the sunset and evening, the F-layer is lifted up $(\boldsymbol{E} \times \boldsymbol{B}$ drift $)$, owing to the eastward E-field generated by the F-region dynamo. The generated E-field depends on the zonal wind $(U)$ and E-region conductivity:

$E_{z}=U y \times B_{0}\left(\sum_{F} /\left(\sum_{F}+\sum_{E}\right)\right)$,

where $U_{y}$ is the thermospheric zonal wind (at $\sim 200 \mathrm{~km}$ ) and $B_{0}$ is the Earth's magnetic field intensity, and $\sum_{F}$ and $\sum_{E}$ are the integrated conductivities of the E- and F-regions (Abdu et al., 2003). Therefore the day-to-day variability of $h^{\prime} F$ is mainly caused by the zonal wind system in the lower thermosphere. If the Kelvin waves penetrate the MLT region even to E-region heights (100 to $120 \mathrm{~km}$ ), they could modulate the local diurnal tidal wind system (mainly zonal), resulting in a variation in the electron conductivity. If the waves penetrate even higher, to 150 to $200 \mathrm{~km}$, they could modulate directly the lower thermosphere zonal wind speed, resulting in direct modulation of the $\boldsymbol{E} \times \boldsymbol{B}$ drift. Since the equatorial F-region plasma bubble formation depends directly on the upward drift velocity, the Kelvin waves could play an important role in the generation of equatorial plasma bubbles.

The purpose of the present paper is, therefore, to investigate whether there is a dynamical coupling between the mesosphere and ionosphere through planetary scale waves. Signatures of the planetary waves have been studied both in the ionosphere and mesosphere individually. However the coupling processes are not well understood. For the present study, the F-region virtual bottom height, $h^{\prime} F$, measured by ionosonde and MLT winds measured by meteor radar are used. In order to identify the phase velocity and propagation direction of the waves, the data from two meteor radars separated by a distance of $2400 \mathrm{~km}$ were compared.

\section{Observations}

A digital ionospheric sounder (DPS-4) is operated at Fortaleza $\left(3.9^{\circ} \mathrm{S}, 38.4^{\circ} \mathrm{W}\right.$, Geomag. $\left.2.1^{\circ} \mathrm{S}\right)$. This is a wide-band pulsed radar system with a $500 \mathrm{~W}$ peak power transmitter and a precise fast-switching frequency synthesizer, covering the frequency range from 0.5 to $30 \mathrm{MHz}$. One ionogram is taken at each 10-minute interval. The ionospheric parameter used in the present analysis is the minimum virtual height of the Flayer $\left(h^{\prime} F\right)$. The Cariri SkiYmet meteor radar is operated at São João do Cariri $\left(7.4^{\circ} \mathrm{S}, 36.5^{\circ} \mathrm{W}\right)$, hereafter Cariri. This is a pulsed radar operating at $35.24 \mathrm{MHz}$ with an interferometric receiver antenna array, similar to the radar in operation at Cachoeira Paulista (Lima et al., 2005). The zonal and meridional winds were estimated in one-hour time bins for 7 atmospheric layers of 4-km thickness, with a height overlap of $1 \mathrm{~km}$ between adjacent layers. The SkiYmet meteor radar at Ascension Island $\left(7.9^{\circ} \mathrm{S}, 14.4^{\circ} \mathrm{W}\right)$, hereafter Ascension, operates at a frequency of $43.5 \mathrm{MHz}$. A description of the 


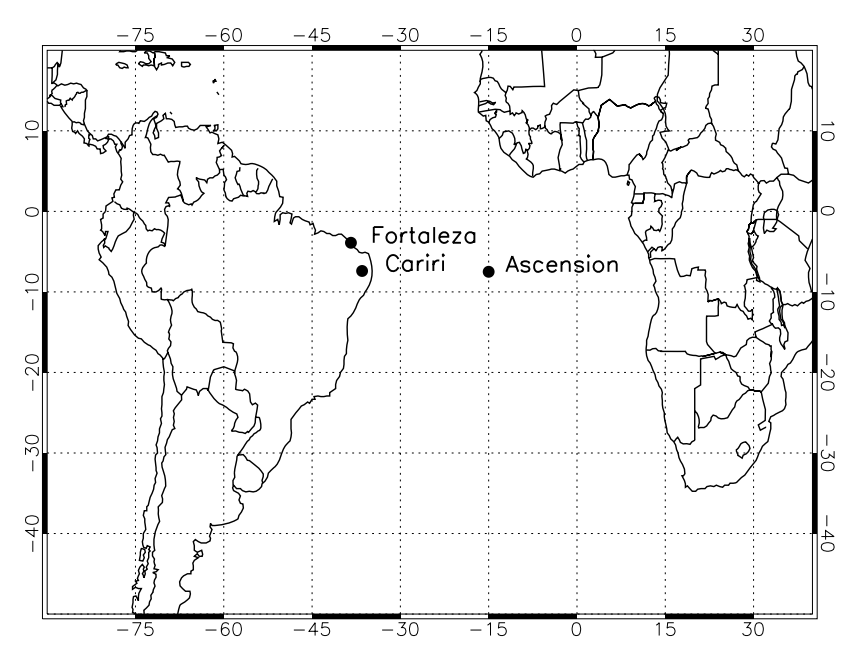

Fig. 1. Geographic locations of the observation sites.

data processing for this radar has been presented elsewhere (Pancheva et al., 2004).

The Cariri meteor radar started to collect wind data in June 2004. The Fortaleza ionosonde and Ascension meteor radar took data on a routine basis throughout 2004. For the present study, therefore, data from 1 July (day number 183) to 31 December (day-366) are used. Cariri and Ascension are located in the same latitudinal zone but longitudinally separated by $2400 \mathrm{~km}$, which makes it possible to observe phase differences in the temporal variation between the two sites. The longitudinal distance between Fortaleza and Cariri is about $200 \mathrm{~km}$, negligible for our purpose. For reference the locations of three observation sites are shown in Fig. 1.

\section{Results}

Day-to-day variability of the F-layer virtual bottom height $\left(h^{\prime} F\right)$ observed at Fortaleza from 1 July (day-183) to 31 December (day-366), 2004, are shown in Fig. 2. As mentioned in the previous section, the F-layer is uplifted after sunset, owing to the F-region dynamo process generated by the thermospheric zonal wind. In order to see the uplifting, we chose $h^{\prime} F$ at a fixed local time. Abdu et al. (2006a) used evening vertical drift velocity to see the effect. We used $h^{\prime} F$ because tabulated data is readily available. In the present study we chose a local time of 20:00 LT (23:00 UT), when $h^{\prime} F$ reaches its maximum height on most nights. As seen in the figure, $h^{\prime} F$ shows significant day-to-day variation within a range of 200 to $350 \mathrm{~km}$. During the period of days 270300 , peak-to-peak variation is more than $60 \mathrm{~km}$. From day 208 to day $220, h^{\prime} F$ remained at a lower level $(\sim 210 \mathrm{~km})$. This might be related to a strong magnetic storm $\left(K_{p} \sim 7-\right.$ 8) which occurred on days 207-209 (25-27 July). In Fig. 3 $A_{p}$ indices (daily values) are plotted as a reference. A similar magnetic storm occurred on days 313-315 (8-10 Novem-
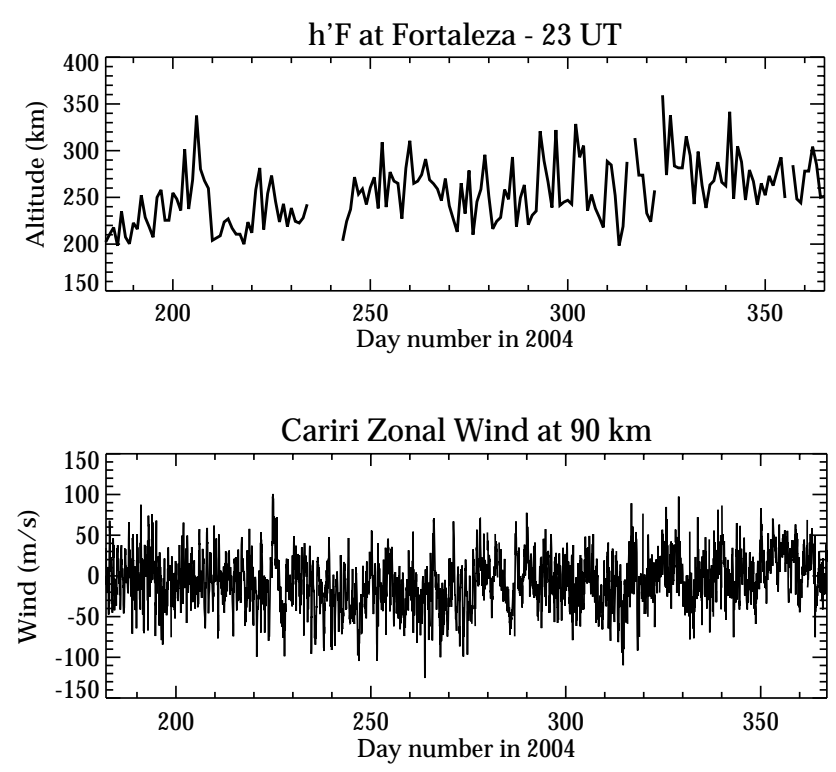

Fig. 2. (Top) Ionospheric F-layer $h^{\prime} F$ time series at 23:00 UT (20:00 LT) observed at Fortaleza, and (Bottom) zonal wind at $90 \mathrm{~km}$ height observed at Cariri, from 1 July to 31 December 2004.

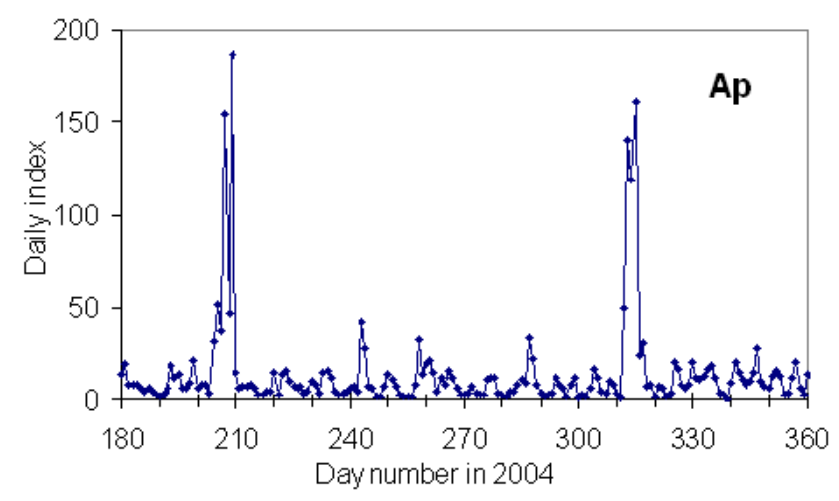

Fig. 3. Planetary index Ap from July to December 2004.

ber), but with less effect on $h^{\prime} F$. Mesospheric zonal winds observed at Cariri are also shown in Fig. 2. Hourly average plots show a large diurnal variation. Furthermore, there are several distinct wave-like modulations with an amplitude of about $30 \mathrm{~m} / \mathrm{s}$. During the period 23 August to 1 October (days 235-275) and 16 October to 15 November (days 290320 ), the background wind was westward with a speed of $20-30 \mathrm{~m} / \mathrm{s}$. The mesospheric meridional wind (not shown in the figure), on the other hand, did not show significant wavelike oscillations except for the diurnal oscillation and some sporadic 2-day oscillations.

In order to investigate the wave-like oscillations, their period and duration, a wavelet spectral analysis was applied to the $h^{\prime} F$ time series. In Fig. 4 a Morlet wavelet power spectrum for a period from 2 to 16 days as a function of the day of the year is shown for $h^{\prime} F$. Since there is only one sample 

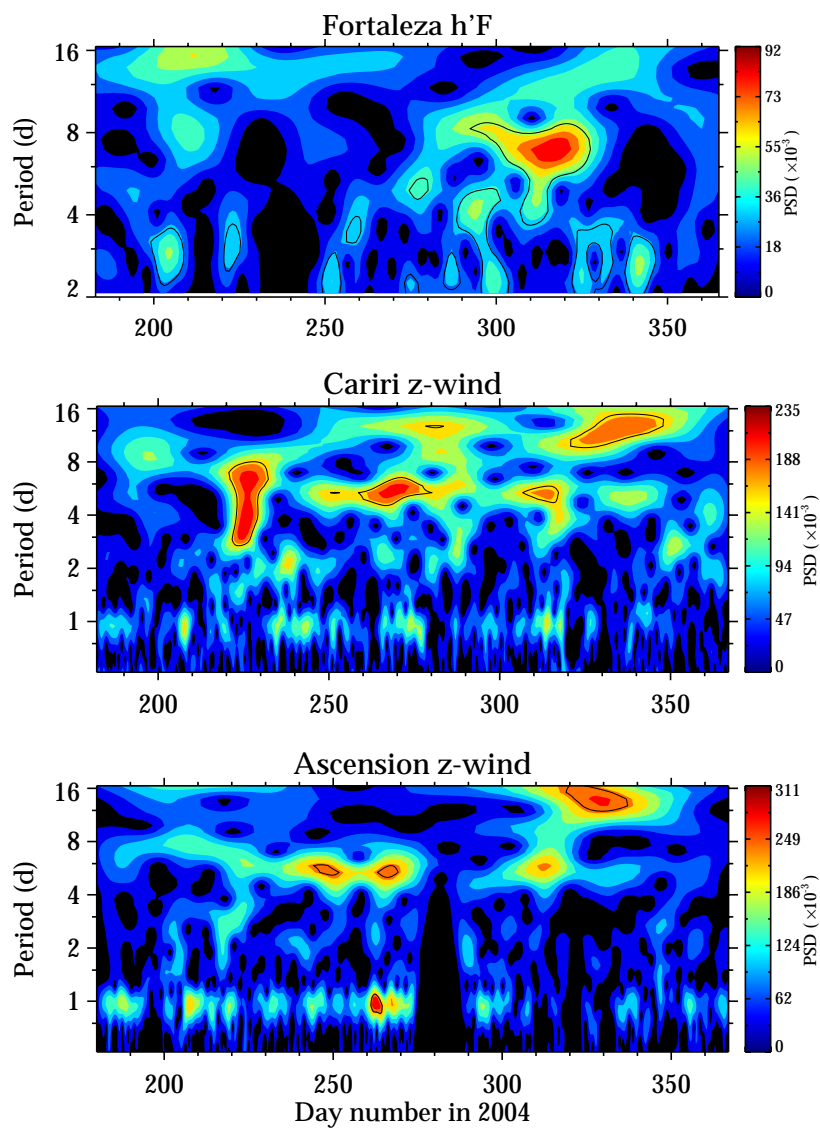

Fig. 4. Wavelet power spectrum of the ionospheric $h^{\prime} F$ day-to-day variation at 23:00 UT at Fortaleza (top), the zonal winds at $90 \mathrm{~km}$ at Cariri (middle) and at Ascension Island (bottom). The color shade shows spectral power density. The full lines indicate the $90 \%$ significance level.

per day in the $h^{\prime} F$ time series, the spectrum cuts off for periods of less than 2 days. From the $h^{\prime} F$ spectrum several kinds of wave packets with periods between 3 and 16 days can be seen. The strongest oscillation with a period of 6-8 day (hereafter "-d") is seen around days 280-330. As mentioned before, this was a partly magnetic storm period (days 313-315). Therefore, the 6-8-day oscillation could be partly storm-related. Around days 200-210, 3-day, 8-day and 16day oscillations can be seen. This could also be due to the magnetic storm effect. Away from the storm periods, there is a 3-4-day oscillation around days 220-230. This should not be related to the storm aftereffect. Another 3-4-day oscillation can be seen at around days 250-260 and days 290-300.

The wavelet analysis for the zonal winds at $90 \mathrm{~km}$ over Cariri and Ascension is also shown in Fig. 4. Both sites show quite similar power spectra, indicating a common wind pattern. The most prominent feature is a 6-day oscillation, extending from day-250 to day-340. Note that the Ascension data from days $275-285$ is missing, owing to equipment failure. During days 220-230 a rather wide spectrum can be
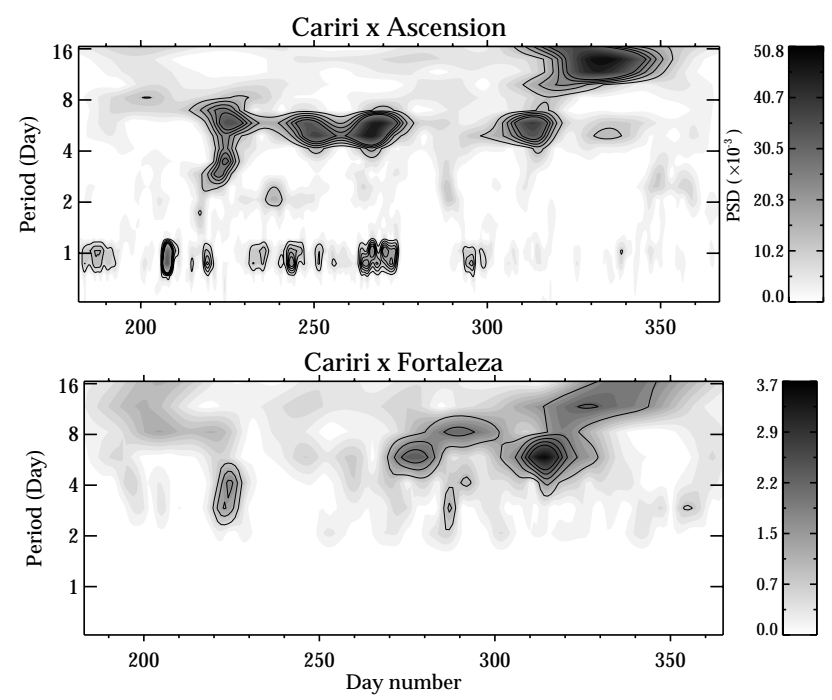

Fig. 5. Cross-wavelet power spectrum between the $90-\mathrm{km}$ zonal winds at Cariri and Ascension Island (top), and between the MLT zonal wind at Cariri and the ionospheric $h^{\prime} F$ at Fortaleza (bottom). The full lines indicate the $90 \%$ significance level.

seen for both locations. There appears to be a superposition of two waves, one 3-4-day and the other 6-8-day. A long period oscillation (12-16-day) can also be seen in the days 320-350 period.

In order to search for common period oscillations among the three time series, a cross-power wavelet analysis was applied, the results from which are shown in Fig. 5. The crosspower spectrum for Cariri and Ascension shows clear evidence for the 6-d oscillation during the period of days 220 270. The 3-4 day oscillation at days 220-230 is also evident. For the analysis of $h^{\prime} F$ and the wind at Cariri, it is necessary to create a time series with the same time interval. For this purpose daily averaged wind data were used. Several common wave packets can be seen in the figure, i.e. a 3-4-day oscillation during days 220-230, a 6-day oscillation for days 270-280 and days 300-330, and a 12-16-day oscillation for days 320-350. The existence of common period oscillations in the three time series, 3-4-day at days 220-230 and 6-day at days $280-330$ is noteworthy.

\section{Discussion}

From the spectral analysis, we found common oscillation patterns in the mesospheric winds at Cariri and Ascension. The two stations are separated by approximately $22.1^{\circ}$ in longitude $(2430 \mathrm{~km})$. Therefore the observed similar oscillations, with 3-4-day, 6-day, and 12-16-day periods, should not be excited locally, but must be due to planetary scale waves. In the present work, we focus our discussion on the 3-4-day and 6-day waves. 

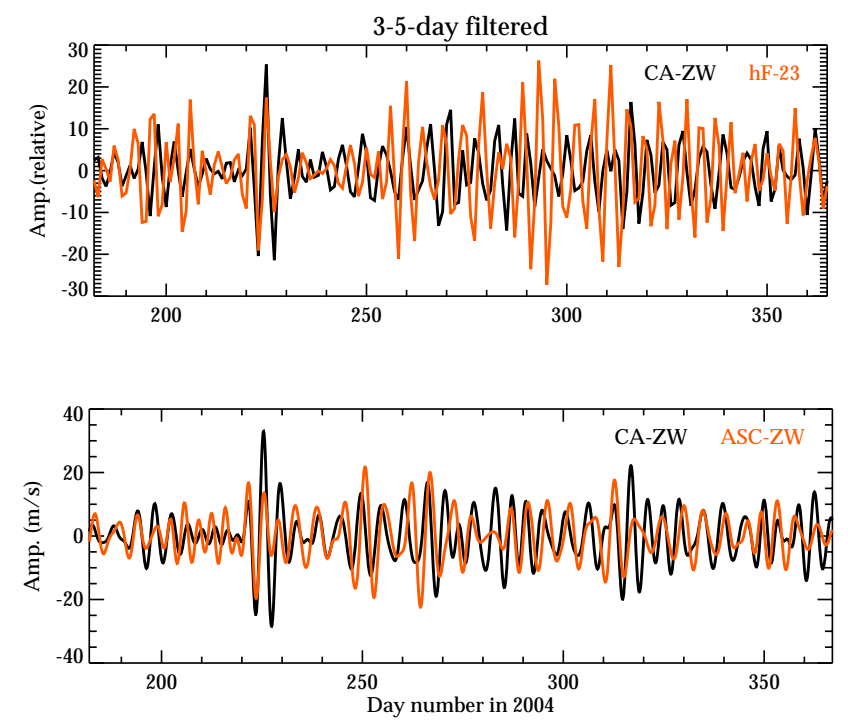

Fig. 6. Amplitude of oscillation of 3-5-day filtered $h^{\prime} F$ at Fortaleza (red line) and zonal wind at Cariri (black line) (top), and zonal wind at Ascension Island (red) and Cariri (black) (bottom). There is no wind data for Ascension from day 275 to day 285.

\section{$4.13-4$ day wave}

In order to find the amplitude and phase of the wave, a bandpass filter centered on 4 days with a full width of 3 days (3-5-days), was applied to the Fortaleza $h^{\prime} F$, Cariri and Ascension zonal wind time series for days $180-366$. The results are shown in Fig. 6. The interval between days 220230 shows the most prominent oscillation not only for Cariri and Ascension but also for Fortaleza $h^{\prime} F$. The amplitude of oscillation at Cariri reached $20 \mathrm{~m} / \mathrm{s}$ and lasted for 2 to 3 cycles and then disappeared. It is interesting to note that the $h^{\prime} F$ oscillation at Fortaleza and the Cariri wind oscillation are almost in phase during this period. The Cariri and Ascension zonal winds are also almost in phase. From a cross-correlation analysis between the two series, it can be seen that the Cariri oscillation phase leads Ascension by approximately $20^{\circ}$, equivalent to $5 \mathrm{~h}$ in the case of a 4-day period. Considering the distance between Cariri and Ascension, this corresponds to a propagation velocity of +140 $( \pm 20) \mathrm{m} / \mathrm{s}$, eastwards. From the vertical phase propagation of the zonal wind, the vertical wavelength was estimated at around $45 \pm 3 \mathrm{~km}$ for both Cariri and Ascension. Further, it is interesting to note that the meridional winds at both Cariri and Ascension Island did not show any 3-4 day oscillation during this period. These facts suggest that the wave observed might be a 3.5-day Ultra Fast Kelvin (UFK) wave. As mentioned before, Forbes (2000) predicted the penetration of a UFK wave into the ionosphere. Miyoshi and Fujiwara (2006) showed in their general circulation model that the UFK wave could propagate upward from the troposphere to the lower thermosphere with a duration of 10-60 days.
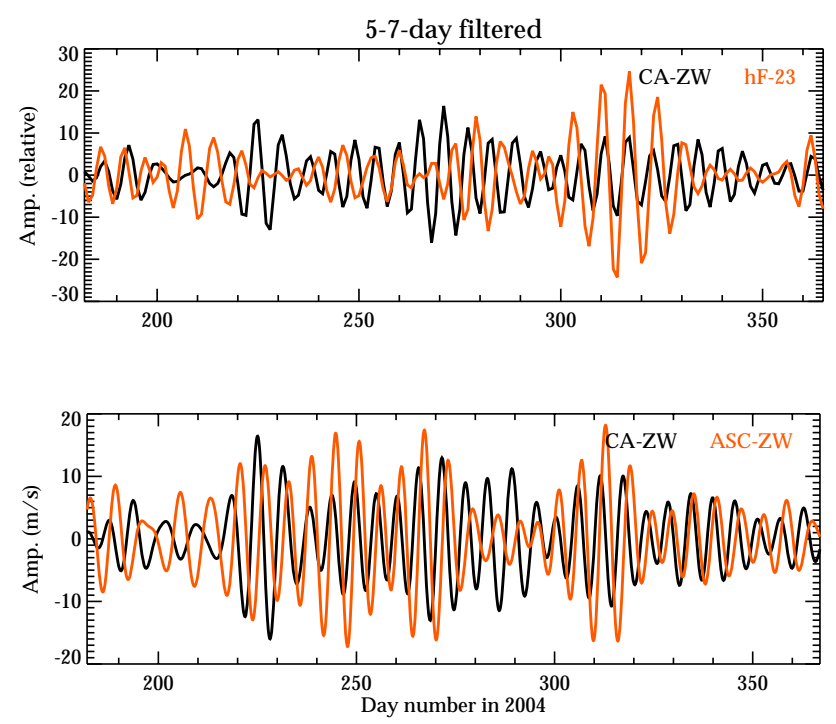

Fig. 7. Amplitude of the oscillation of the 5-7-day filtered $h^{\prime} F$ at Fortaleza (red line) and zonal wind at Cariri (black line) (top), and zonal wind at Ascension Island. (red) and Cariri (black) (bottom). There is no wind data for Ascension from day 275 to day 285.

Our present results agree with their model prediction. If this is really the UFK wave, then this is the first time it has been observed in the ionosphere. Further observational evidence is needed to confirm this.

\subsection{6-day wave}

A band-pass filter centered on 6-days, with a width of 3 days (5-7 days), was also applied to the Fortaleza, Cariri and Ascension time series. The results are shown in Fig. 7. Fortaleza $h^{\prime} F$ and Cariri wind show a common large amplitude oscillation between days 305 and 325 . It should be noted that the two series are almost in phase. The Cariri and Ascension winds showed common oscillation features during the intervals of days 260-280 and days 305-320. This means that a common oscillation for the mesospheric winds and $h^{\prime} F$ happened during the period of days 305-325. In order to see wave characteristics of the 6-day oscillation for the day 305325 period, the vertical wavelength of the 6-day wave was calculated. In Fig. 8, the phase of maximum of the zonal wind (6-d period component) is shown as a function of height from 81 to $99 \mathrm{~km}$. It shows downward phase propagation, indicating upward energy transport, with a vertical wavelength of $50 \pm 5 \mathrm{~km}$ for Cariri and $45 \pm 4 \mathrm{~km}$ for Ascension. Also seen is the phase difference of $1.3 \pm 0.5$ days between Cariri and Ascension at $90 \mathrm{~km}$. Considering the background wind velocity ( $\sim 20 \mathrm{~m} / \mathrm{s}$ westwards during the period) this is an eastward propagating wave with a phase velocity of $\sim 40 \mathrm{~m} / \mathrm{s}$ and a vertical wavelength of $\sim 50 \mathrm{~km}$. The horizontal wavelength, therefore, can be estimated to be around $20000 \mathrm{~km}$, which corresponds to a wave number 2 . 


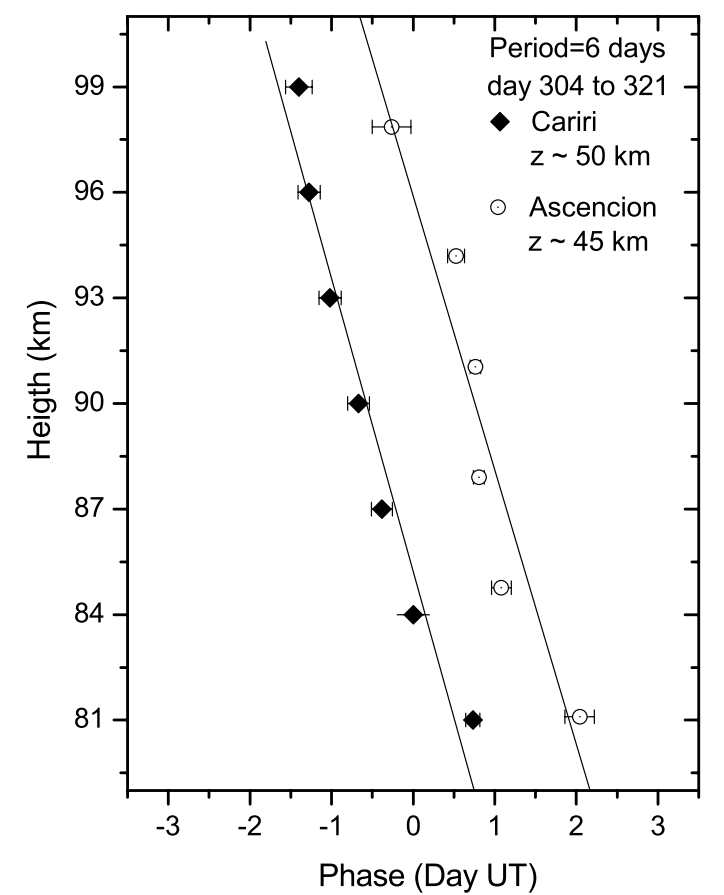

Fig. 8. Phase profiles of the 6-day waves observed in the zonal wind at Cariri and Ascension Island for the period between days 304-321, 2004.

Six-seven day waves in the equatorial MLT region, usually denominated as 6.5-day waves in the literature, have been reported by several groups. Kovalam et al. (1999) observed MLT winds by MF radar from two stations (Pontianak and Christmas Island, with a longitudinal separation of $10000 \mathrm{~km}$ ), and reported that the observed a 6.5-day wave was westward, wave number 1 , with a vertical wavelength of $\sim 65 \mathrm{~km}$ and a horizontal phase velocity of $\sim 80 \mathrm{~m} / \mathrm{s}$. Due to the characteristics of westward propagation and a large vertical wavelength they concluded that it could not be the fast Kelvin wave, but rather a wave generated in the mesosphere with an unstable mode as suggested by Meyer and Forbes (1997). On the other hand, Talaat et al. (2001), from the HRDI/UARS data analysis, concluded that the 6.5-day wave could be a westward propagating Rossby $(1,1)$ normal mode planetary wave with a vertical wavelength of $\sim 60 \mathrm{~km}$. Pancheva et al. (2004) reported that the $\sim 6$ day wave observed at Ascension Island could be a Doppler shifted 5day normal mode, because of the long vertical wavelength $(79 \mathrm{~km})$. Most recently, Kishore et al. (2004) and Lima et al. (2005) also reported the observation of 6.5-day waves. Our present results are similar to the previous works, except for the propagation direction and the wave number. However, it is too early to conclude whether this is the fast Kelvin wave or Rossby wave, or the mixing of the two waves. In the equatorial region the gravity wave activity might induce 6-7 day oscillations, too. From the theory of Fast Kelvin waves it must have a short vertical wavelength $(<20 \mathrm{~km})$ and therefore would be difficult to propagate upwards above the mesosphere (Forbes, 2000). Another question is that the horizontal distance between Cariri and Ascension $(\sim 2400 \mathrm{~km}$, corresponds to only $6 \%$ of the Earth's diameter) may be too short to unambiguously determine the phase velocity and direction. These points leave the definition of the propagation direction as an open question. Further investigations, including at least three observation sites around the equator, are necessary.

The 6-day wave feature observed in both the mesosphere and ionosphere during days 305-325 (31 October to 20 November) is worthy of further investigation. Recently, Abdu et al. (2006a) presented evidence for existence of planetary wave oscillations (6.5-day and 14-day) in the equatorial ionosphere. Further study by Abdu et al. (2006b) indicates simultaneous 6-day wave features in the day-to-day variation of the equatorial F-region vertical drift velocity and the mesospheric winds at low-middle latitudes. It is interesting to note that they observed this in November 2002. Our present results also showed similar 6-day waves in both the mesospheric wind and ionospheric $h^{\prime} F$ in November 2004. Since this occurred during the magnetically disturbed period, a possible storm effect on the $h^{\prime} F$ oscillation cannot be ruled out. The disturbed condition continued for 4 days, days 312 315. During this period, $h^{\prime} F$ at 23:00 UT was kept lower, indicating an effect of the disturbance dynamo during this period. It lasted for 3 days. However, the 6-day oscillation observed in the present study has a much longer period, around 20 days. Therefore, we believe that the observed 6day oscillation in $h^{\prime} F$ is mainly correlated to the mesospheric zonal wind oscillation. The question of why the 6-day oscillation in $h^{\prime} F$ did not occur in August-September when the mesospheric winds showed such oscillations merits further examination. Nevertheless, the 6-day wave also seems to be an important factor with respect to the evening rise in the ionospheric F-region.

\section{Conclusions}

From simultaneous observations of ionospheric $h^{\prime} F$ at Fortaleza and equatorial MLT winds from two longitudinally distant sites, Cariri and Ascension Island, we found that on some occasions there are common period oscillations in the zonal winds and $h^{\prime} F$, i.e. 3-4-day, 6-day and 12-16-day. The 3-4-day oscillation was observed during the period 7 to 17 August 2004 (days 220-230). From the vertical phase propagation and phase difference between the observation sites, we conclude that this could be a 3.5-day Ultra Fast Kelvin wave. The 6-day oscillation was observed during the period from 31 October to 20 November (days 305-325) for both $h^{\prime} F$ and mesospheric zonal winds. Although this occurred during a geomagnetic storm period (8-10 November), the wave characteristics obtained from the vertical phase 
structures indicates that the wave involved could be 6.5-day waves, as identified by several previous studies (Pancheva et al., 2004). The global scale vertically propagating waves could drive electric currents and plasma drifts with the period of these waves. The 3.5-day and 6.5-day waves could propagate upwards from the stratosphere to the mesosphere and lower thermosphere, and could interact with the ionosphere, modulating E-region conductivity and the F-region dynamo. We believe that this mechanism might be important in relation to equatorial plasma bubble formation and its day-to-day variability.

Acknowledgements. The authors thank T. Ogawa at STEL, Nagoya University, J. Fechine at INPE, and S. Sridharam at RISH, Kyoto University, for their useful discussions. Thanks are also due to those people working at the Cariri, Fortaleza and Ascension Island observation sites. The present work was made under their constant efforts. Wavelet software used in the present work was provided by C. Torrence and G. Compo and is available at http: //paos.colorado.edu/research/wavelets/. This work was partially supported by the Conselho Nacional de Desenvolvimento Científico e Tecnológico, CNPq and the Fundação Amparo à Pesquisa do Estado de São Paulo, FAPESP, under the contract number 05/50482-5.

Topical Editor M. Pinnock thanks J. Lastovika and another referee for their help in evaluating this paper.

\section{References}

Abdu, M. A., MacDougall, J. W., Batista, I. S., Sobral, J. H. A., and Jayachandran P. T.: Equatorial evening prereversal electric field enhancement and sporadic E-layer disruption: A manifestation of E- and F-region coupling, J. Geophys Res., 108, 1254, doi:10.1029/2002JA009285, 2003.

Abdu, M. A., Ramkumar, T. K., Batista, I. S., Brum, C. G. M., Takahashi, H., Reinisch, B. W., and Sobral, J. H. A.: Mesosphere E- and F-Region coupling, and Planetary wave effects in the Equatorial Ionosphere, J. Atmos. Solar Terr. Phys., 68, 509522, 2006a.

Abdu, M. A., Batista, P. P., Batista, I. S., Brum, C. G. M., Carrasco, A. J., and Reinisch, B. W.: Planetary wave oscillations in mesospheric winds, equatorial evening prereversal electric field and spread F, Geophys. Res. Lett., 33, L07107, doi:10.1029/2005GL024837, 2006b.

Brown, G. M. and Williams, D. C.: Pressure variations in the stratosphere and ionosphere, J. Atmos. Terr. Phys., 33, 1321-1328, 1971.

Chen, P. R.: Two-day oscillation of the equatorial ionization anomaly, J. Geophys. Res., 97, 6343-6357, 1992.

Forbes, J. M. and Leveroni, S.: Quasi 16-day oscillation in the ionosphere, Geophys. Res. Lett., 19, 981-984, 1992.

Forbes, J. M., Guffee, R., Zhang, X., Fritts, D., Riggin, D., Manson, A., Meek, C., and Vincent, R. A.: Quasi 2-day oscillation of the ionosphere during summer 1992, J. Geophys. Res., 102, 73017305, 1997.

Forbes, J. M.: Wave coupling between the lower and upper atmosphere: case study of an ultra-fast Kelvin Wave, J. Atmos. Solar Terr. Phys., 62, 1603-1621, 2000.
Haldoupis, C., Pancheva D., and Mitchell, N. J.: A study of tidal and planetary wave periodicities present in midlatitude sporadic E-layers, J. Geophys. Res., 109, A02302, doi:10.1029/2003JA010253, 2004.

Hirota, I.: Kelvin waves in the equatorial middle atmosphere observed by the Nimbus 5 SCR., J. Atmos. Sci., 36, 217-222, 1979.

Holton, J. R.: An introduction to Dynamic Meteorology, International Geophysics Series, Academic Press, 1979.

Kishore, P., Namboothiri, S. P., Igarashi, K., Gurubaran, S., Sridharan, S., Rajaram, R., and Ratnam, M. V.: MF radar observations of 6.5-day wave in the equatorial mesosphere and lower thermosphere, J. Atmos. Solar-Terr. Physics, 66, 507-515, 2004.

Kovalam, S., Vincent, R. A., Reid, I. M., Tsuda, T., Nakamura, T., Ohnishi K., Nuryanto, A., and Wiryosumarto, H.: Longitudinal variations in planetary wave activity in the equatorial mesosphere, Earth Planets Space, 51, 665-674, 1999.

Lastovicka, J. and Sauli, P.: Are planetary wave type oscillations in the $\mathrm{F} 2$ region caused by planetary wave modulation of upward propagating tides?, Adv. Space Res., 24, 1473-1476, 1999.

Lieberman, R. S. and Riggin, D.: High resolution Doppler imager observations of Kelvin waves in the equatorial mesosphere and lower thermosphere, J. Geophys. Res., 102, 26 117-26 130, 1997.

Lima, L. M., Batista, P. P., Clemesha, B. R., and Takahashi, H.: The 6.5-day oscillations observed in meteor winds over Cachoeira Paulista $\left(22.7^{\circ} \mathrm{S}\right)$, Adv. Space Res., 36, 2212-2217, 2005.

Meyer, C. K. and Forbes, J. M.: A 6.5-day westward propagating planetary wave: Origin and characteristics, J. Geophys. Res., 102, 26 173-26 178, 1997.

Miyoshi, Y. and Fujiwara, H.: Excitation mechanism of intraseasonal oscillation in the equatorial mesosphere and lower thermosphere, J. Geophys. Res., 111, D14108, doi:101029/2005JD006993, 2006.

Pancheva, D. and Lysenko, I.: Quasi-two-day fluctuations observed in the summer $\mathrm{F}$ region electron maximum, Bulgarian Geophys. J., XIV (2), 41-51, 1988.

Pancheva, D., Mitchell, N., Clark, R., Drobjeva, J., and Lastovicka, $\mathrm{J}$.: Variability in the maximum height of the ionospheric F2-layer over Millstone Hill (September 1998-March 2000); influence from below and above, Ann. Geophys., 20, 1807-1819, 2002, http://www.ann-geophys.net/20/1807/2002/.

Pancheva, D., Mitchell, N. J., and Younger, P. T.: Meteor radar observations of atmospheric waves in the equatorial mesosphere/lower thermosphere over Ascension Island, Ann. Geophys., 387-404, 2004.

Parish, H. F., Forbes, J. M., and Kamalabadi, F.: Planetary wave and solar emission signatures in the equatorial electrojet, J. Geophys. Res., 99, 355-368, 1994.

Salby, M. L., Hartmann, D. L., Bailey, P. L., and Gille, J.C.: Evidence for equatorial Kelvin modes in Nimbus-7 LIMS, J. Atmos. Sci., 41, 220-235, 1984.

Takahashi, H., Buriti, R. A., Gobbi, D., and Batista, P. P.: Equatorial planetary wave signatures observed in mesospheric airglow emissions., J. Atmos. Solar Terr. Phys., 64, 1263-1272, 2002.

Takahashi, H., Lima, L. M., Wrasse, C. M., Abdu, M. A., Batista, I. S., Gobbi, D., Buriti, R. A., and Batista, P. P.: Evidence on 2-4 day oscillations of the equatorial ionosphere $h^{\prime} F$ and mesospheric airglow emissions, Geophys. Res. Lett., 32, L12102, doi:101029/2004GL022318, 2005. 
Talaat, E. R., Yee, J.-H., and Zhu, X.: Observations of the 6.5-day wave in the mesosphere and lower thermosphere, J. Geophys. Res., 106, 20 715-20 723, 2001.

Vincent, R. A.: Long-period motions in the equatorial mesosphere, J. Atmos. Terr. Phys., 55, 1067-1080, 1993.
Wallace, J. and Kousky, V.: Observational evidence of Kelvin waves in the tropical stratosphere, J. Atmos. Sci., 25, 900-907, 1968. 